\title{
Sleep disturbances among physicians during COVID-19 pandemic
}

\author{
Yasser H. Alnofaiey ${ }^{1}$, Haneen A. Alshehri ${ }^{*}$ (D), Maram M. Alosaimi ${ }^{2}$, Shrooq H. Alswat ${ }^{2}$, Raghad H. Alswat ${ }^{2}$, \\ Rahaf M. Alhulayfi' ${ }^{2}$, Meteb A. Alghamdi ${ }^{2}$ and Reem M. Alsubaie ${ }^{3}$
}

\begin{abstract}
Objectives: To assess prevalence and related factors of sleep disturbances among Saudi physicians during COVID-19 pandemic. Data were collected through a questionnaire including items about demographic characters, knowledge about covid-19 and items to assess sleep quality that were extracted from Pittsburgh Sleep Quality Index (PSQI) scale.

Results: Prevalence of sleep disorders was 43.9\%, doctors in the age group of 31-40 years, associate consultants had a significant higher prevalence of sleep disorders. Medical interns and laboratory/pathology/microbiology doctors had a significant more difficulty in fall asleep during COVID-19, and internists and surgeons had a significant higher percent of those who used sleeping pills. Resident doctors had a significant higher percent of having trouble in staying awake, and residents and consultants had a significant higher percent of those who suffered decreased sleep duration. Sleep quality during COVID-19 was very good, fair good and very bad in $23.4 \%, 60 \%$ and $3.5 \%$ of HCW respectively. The study observed a negative impact of COVID-19 pandemic on HCW sleep quality. Hospitals administrations should provide optimal working hours with enough break and employ more doctors during the pandemic. Doctors experiencing sleep problems should have mandatory leaves.
\end{abstract}

Keywords: Sleep, Disturbances, Physicians, COVID-19, Pandemic, Saudi

\section{Introduction}

COVID-19 appeared in Wuhan, China, in December 2019 and rapidly spread to become a global pandemic. [1-4]. Clinical manifestations include mainly fever (99\%), fatigue (70\%), dry cough (60\%), myalgia (44\%), and dyspnea at the onset of the disease $[5,6]$. Treatment of COVID-19 is mostly supportive and no known effective specific treatment exists [7].

All people during COVID-19 pandemic have fears of getting infected or infecting others [8]. Health care workers face other stresses, such as absence of clear strategy to follow and an increased risk of exposure to aerosols [8].

Sleep disorders involve problems either in the quality, timing or amount of sleep $[9,10]$. Studies from China

*Correspondence: Haneenalshehri511@gmail.com

${ }^{2}$ Medical Student, KSA, Taif University, Taif, Saudi Arabia

Full list of author information is available at the end of the article identified that healthcare workers were at high risk for poor sleep quality during COVID-19 epidemic [11], and high prevalence of post-traumatic stress syndrome and poor sleep quality [12]. No published studies addressed the problem of sleep quality during COVID-19 epidemic in Saudi Arabia. The current study aimed to assess prevalence and related factors of sleep disturbances among Saudi physicians of the Western province of Kingdom of Saudi Arabia (KSA) during COVID-19 pandemic.

\section{Main text \\ Methods}

Study design and setting, and time frame: a cross-sectional survey was carried out in health care settings in the Western province of Saudi Arabia that included the Mecca, Jeddah, and Taif cities. The study was done during the period the period of May 2020 to August 2020.

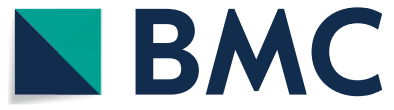

(c) The Author(s) 2020. This article is licensed under a Creative Commons Attribution 4.0 International License, which permits use, sharing, adaptation, distribution and reproduction in any medium or format, as long as you give appropriate credit to the original author(s) and the source, provide a link to the Creative Commons licence, and indicate if changes were made. The images or other third party material in this article are included in the article's Creative Commons licence, unless indicated otherwise in a credit line to the material. If material is not included in the article's Creative Commons licence and your intended use is not permitted by statutory regulation or exceeds the permitted use, you will need to obtain permission directly from the copyright holder. To view a copy of this licence, visit http://creativeco mmons.org/licenses/by/4.0/. The Creative Commons Public Domain Dedication waiver (http://creativecommons.org/publicdomain/ zero/1.0/) applies to the data made available in this article, unless otherwise stated in a credit line to the data. 
Study participants: The study was carried out on Saudi doctors who were willing to participate in the survey. Physicians working in other regions of Saudi Arabia and non-Saudi doctors were excluded from our study.

Sample size and sampling method: a minimum sample size of 327 was calculated with 95\% confidence level, 5\% margin of error and power of study ( $\beta$-error) at $80 \%$ considering the values derived from the pilot study. A mixture of cluster, convenience and snowball sampling was followed to acquire the minimum sample size.

Data collection: a pre-tested and validated questionnaire was used. Social media tools were used to broadcast the relevant link of the questionnaire.

The questionnaire included items to collect demographic data, and knowledge about COVID-19. Knowledge items were about (a) inhalation of droplets from sneezing, coughing, or talking of an infected person (b) contact with something contaminated by an infected person, (c) the incubation period of the virus, (d) contact with an asymptomatic person and possibility of infection, and (e) if there are already targeted drugs that could cure the disease. For all questions responses to items related to knowledge regarding COVID-19 were recorded and each correct response were given a score of ' 1 ' and wrong answers were given score ' 0 ' (11). Thus, the maximum score one could get is 6 . The scores were then categorized based on the percentages into 'Good' (80-100\%), Fair $(60-79 \%)$ and Poor $(<59 \%)$.

For assessing the sleep quality, five items were extracted from Pittsburgh Sleep Quality Index (PSQI) scale [13], and these include: Subjective sleep quality, difficulty in starting sleep within $30 \mathrm{~min}$, easy waking during sleep and early waking in the morning, use of sleep medication, and the sleep duration, within 1-month lasted. A very good quality sleep is defined when the subject experiences all of the five characteristics mentioned: (a) Sleeping more time while in bed (at least $85 \%$ of the total time in bed), (b) Falling asleep in 30 min or less, (c) Sleeping for more $7 \mathrm{~h}$ or more, (d) Falling back asleep within 20 min after getting up, and (e) Waking up-for five minutes or longer-no more than once a night. Subjects were asked to rate the quality of their sleep based on the above five points as 'very good,' 'fairly good,' 'fairly bad' and 'very bad'. Single-item sleep measures have been used in previous studies $[12,14]$.

Validation of the Questionnaire: the questionnaire included items that covered knowledge regarding Covid 19 infection and measured the sleep quality. The items related to sleep quality was adopted from Pittsburgh Sleep Quality Index (PSQI) scale by Buysse et al. [13]. Validation of this questionnaire was done using focus group discussion, expert evaluation, pilot study, reliability and validity assessment etc. Three experts in the field of COVID 19 and one biostatistician were involved in the validation of our questionnaire. A pilot study was done on 15 participants and the data obtained was used for reliability and validity analysis. Content validity, face validity, and construct validity of the developed questionnaire were examined. Content validity and face validity were established by expert evaluation and focused group discussions.

Construct validity was established by exploratory factor analysis with varimax rotation to test the hypothesized domain structure and examine its substructure. Items with correlation coefficient $>0.7$ were omitted. Internal consistency was examined, but test/retest reliability could not be performed because of paucity of time. The homogeneity of the question items in each domain was evaluated using Cronbach's $\alpha$ coefficient. A coefficient of 0.7 or higher is preferred for a questionnaire to be internally consistent.

Data analysis: data analysis done by the SPSS program version 23. Descriptive statistics in the form frequencies and percentages were used to describe the demographics; sleep characteristics and COVID-19 related knowledge among the study participants. Means and Standard deviations (mean $\pm S D$ ) were used to represent continuous variable and Pearson's Chi-Square test was used to test the association between categorical variables.

\section{Results}

Of the participants, 340 (73.6\%) had an age ranging from 23-30 years, 235 (50.9\%) were females, 202 (43.7\%) were from Taif city, 256 (55.4\%) were residents, and 18.6\% had an internal medicine specialty. The mean knowledge score in our study was found to be $4.23 \pm 1.06$ thus showing 'good' scores by $78.1 \%(\mathrm{n}=361), 12.1 \%$ showed fair knowledge and $9.7 \%$ gave poor scores. When the relationship of the knowledge scores and difference sociodemographic characteristics were assessed, there was no statistically significant difference observed with the gender, age, position, specialty and region of practice of doctors (Table 1, Additional file 1: Figure S1).

The prevalence of sleep disorders in our study was found to be $43.9 \%$ during COVID-19 pandemic. When the relationship of sleep disorders with different sociodemographic and work-related characteristics was compared, there was significant association observed with age, position and specialty. Doctors who belonged to age group of 31-40 years showed more prevalence of sleep disorders (63\%) compared to other age groups $(p=0.002)$. When the prevalence of sleep disorders with different position of doctors at hospitals was assessed, it was found that associate consultants and residents showed more sleep disorders than other groups with a highly statistically significant association. 
Table 1 Relationship of Knowledge about COVID-19 with gender, age and designation of participants

\begin{tabular}{|c|c|c|c|c|c|c|c|}
\hline \multirow[t]{2}{*}{ Variable } & & \multicolumn{3}{|c|}{ Knowledge } & \multirow[t]{2}{*}{ Total } & \multirow[t]{2}{*}{$x^{2}$} & \multirow[t]{2}{*}{$p$ value } \\
\hline & & Good & Fair & Poor & & & \\
\hline \multicolumn{8}{|l|}{ Gender } \\
\hline \multirow[t]{2}{*}{ Female } & $\mathrm{N}$ & 182 & 26 & 19 & 227 & 1.261 & 0.532 \\
\hline & $\%$ & $80.2 \%$ & $11.5 \%$ & $8.4 \%$ & $49.1 \%$ & & \\
\hline \multirow[t]{2}{*}{ Male } & $\mathrm{N}$ & 179 & 30 & 26 & 235 & & \\
\hline & $\%$ & $76.2 \%$ & $12.8 \%$ & $11.1 \%$ & $50.9 \%$ & & \\
\hline \multicolumn{8}{|l|}{ Age } \\
\hline \multirow[t]{2}{*}{$23-30$ years } & & 266 & 41 & 33 & 340 & 4.476 & 0.613 \\
\hline & & $78.2 \%$ & $12.1 \%$ & $9.7 \%$ & $73.6 \%$ & & \\
\hline \multirow[t]{2}{*}{$31-40$ years } & & 67 & 8 & 6 & 81 & & \\
\hline & & $82.7 \%$ & $9.9 \%$ & $7.4 \%$ & $17.5 \%$ & & \\
\hline \multirow[t]{2}{*}{$41-50$ years } & & 12 & 4 & 2 & 18 & & \\
\hline & & $66.7 \%$ & $22.2 \%$ & $11.1 \%$ & $3.9 \%$ & & \\
\hline \multirow[t]{2}{*}{$51-60$ years } & & 16 & 3 & 4 & 23 & & \\
\hline & & $69.6 \%$ & $13.0 \%$ & $17.4 \%$ & $5.0 \%$ & & \\
\hline \multicolumn{8}{|l|}{ Position } \\
\hline \multirow[t]{2}{*}{ Consultant } & $\mathrm{N}$ & 39 & 8 & 4 & 51 & 2.734 & 0.950 \\
\hline & $\%$ & $76.5 \%$ & $15.7 \%$ & $7.8 \%$ & $11.0 \%$ & & \\
\hline \multirow{2}{*}{$\begin{array}{l}\text { Associate consultant/ } \\
\text { Registrar }\end{array}$} & $\mathrm{N}$ & 23 & 5 & 4 & 32 & & \\
\hline & $\%$ & $71.9 \%$ & $15.6 \%$ & $12.5 \%$ & $6.9 \%$ & & \\
\hline \multirow[t]{2}{*}{ Specialist } & $\mathrm{N}$ & 24 & 3 & 3 & 30 & & \\
\hline & $\%$ & $80.0 \%$ & $10.0 \%$ & $10.0 \%$ & $6.5 \%$ & & \\
\hline \multirow[t]{2}{*}{ Resident } & $\mathrm{N}$ & 205 & 28 & 23 & 256 & & \\
\hline & $\%$ & $80.1 \%$ & $10.9 \%$ & $9.0 \%$ & $55.4 \%$ & & \\
\hline \multirow[t]{2}{*}{ Intern } & $\mathrm{N}$ & 70 & 12 & 11 & 93 & & \\
\hline & $\%$ & $75.3 \%$ & $12.9 \%$ & $11.8 \%$ & $20.1 \%$ & & \\
\hline
\end{tabular}

The prevalence of sleep disorders was found to be $53.1 \%$ and $49.6 \%$ in associate consultants and residents respectively $(\mathrm{p}<0.001)$ (Table 2). When the prevalence of SD was examined based on different specialties, anesthetists, Laboratory/Pathology/Microbiology specialists and dentists had the highest prevalence (66.7\%) compared to other specialties with a statistically significant association $(\mathrm{p}=0.024)$ (Additional file 1: Figure S2).

Assessment of different sleep characteristics during COVID-19 is given in Table 3. When the participants' difficulty to fall asleep within $30 \mathrm{~min}$ was measured, it was found that $24.7 \%$ had the difficulty to fall asleep twice or more in a week during COVID-19, compared to $10.2 \%$ before the pandemic with a statistically significant difference $(\mathrm{p}<0.001)$. Difficulty in fall asleep during COVID19 showed a statistically significant association with specialty of the participants, where medical interns and doctors working in laboratory/pathology/microbiology department had significantly more difficulty $(\mathrm{p}=0.002)$. The evaluation of usage of sleeping pills during COVID19 showed that $3.9 \%$ and $10.2 \%$ used it three or more times a week and one or twice week respectively. This usage was more seen in internists (31.9\%) and surgeons (19.1\%) compared to other specialties with a statistically significant association $(\mathrm{p}=0.028)$ (Table 3$)$.

The prevalence of trouble in staying awake while driving, eating meals or engaging in social activity was $6.1 \%$ and $13.9 \%$ in $\geq 3$ times a week and once or twice week respectively. This was significantly more reported in resident doctors $(\geq 3$ times $/$ week $=71.4 \%$ and once/ twice $=68.8 \%)$ compared to other groups $(p=0.002)$. When sleep duration among doctors was measured, $38.1 \%$ reported sleeping for $<6 \mathrm{~h} /$ day during COVID-19 compared to $32.3 \%$ before COVID-19 with a statistically significant difference $(\mathrm{p}<0.001)$. Residents $(45.7 \%)$ and consultants $(43.1 \%)$ showed a significant higher percent of those who suffered decreased sleep duration $(<6 \mathrm{~h})$ during COVID-19 $(\mathrm{p}<0.001)$.

The overall sleep quality during COVID-19 was observed to be very good and fair good in $23.4 \%$ and $60 \%$ of doctors respectively. Only $3.5 \%$ of the doctors were found to have 'very bad' sleep during this pandemic, and this was significantly more prevalent in female doctors (5.3\%) compared to males $(1.7 \%)(\mathrm{p}=0.027)$. 
Table 2 Prevalence of sleep disorders and its relationship with Age, gender and designation of participants

\begin{tabular}{|c|c|c|c|c|c|c|}
\hline \multirow[t]{2}{*}{ Variable } & \multicolumn{2}{|c|}{ Sleep disorder } & \multirow[t]{2}{*}{ Total } & \multirow[t]{2}{*}{$x^{2}$} & \multirow[t]{2}{*}{$p$ value } & \\
\hline & Absent & Present & & & & \\
\hline \multicolumn{7}{|l|}{ Gender } \\
\hline \multirow[t]{2}{*}{ Female } & $N$ & 123 & 104 & 227 & 0.637 & 0.425 \\
\hline & $\%$ & $54.2 \%$ & $45.8 \%$ & $49.1 \%$ & & \\
\hline \multirow[t]{2}{*}{ Male } & N & 136 & 99 & 235 & & \\
\hline & $\%$ & $57.9 \%$ & $42.1 \%$ & $50.9 \%$ & & \\
\hline \multicolumn{7}{|l|}{ Age } \\
\hline \multirow[t]{2}{*}{ 23-30 years } & N & 204 & 136 & 340 & 14.445 & 0.002 \\
\hline & $\%$ & $60.0 \%$ & $40.0 \%$ & $73.6 \%$ & & \\
\hline \multirow[t]{2}{*}{$31-40$ years } & N & 30 & 51 & 81 & & \\
\hline & $\%$ & $37.0 \%$ & $63.0 \%$ & $17.5 \%$ & & \\
\hline \multirow[t]{2}{*}{$41-50$ years } & $\mathrm{N}$ & 11 & 7 & 18 & & \\
\hline & $\%$ & $61.1 \%$ & $38.9 \%$ & $3.9 \%$ & & \\
\hline \multirow[t]{2}{*}{$51-60$ years } & N & 14 & 9 & 23 & & \\
\hline & $\%$ & $60.9 \%$ & $39.1 \%$ & $5.0 \%$ & & \\
\hline \multicolumn{7}{|l|}{ Position } \\
\hline \multirow[t]{2}{*}{ Consultant } & $N$ & 26 & 25 & 51 & 22.200 & $<0.001$ \\
\hline & $\%$ & $51.0 \%$ & $49.0 \%$ & $11.0 \%$ & & \\
\hline \multirow{2}{*}{$\begin{array}{l}\text { Associate consultant/ } \\
\text { Registrar }\end{array}$} & $N$ & 15 & 17 & 32 & & \\
\hline & $\%$ & $46.9 \%$ & $53.1 \%$ & $6.9 \%$ & & \\
\hline \multirow[t]{2}{*}{ Specialist } & $N$ & 17 & 13 & 30 & & \\
\hline & $\%$ & $56.7 \%$ & $43.3 \%$ & $6.5 \%$ & & \\
\hline \multirow[t]{2}{*}{ Resident } & $\mathrm{N}$ & 129 & 127 & 256 & & \\
\hline & $\%$ & $50.4 \%$ & $49.6 \%$ & $55.4 \%$ & & \\
\hline \multirow[t]{2}{*}{ Intern } & $\mathrm{N}$ & 72 & 21 & 93 & & \\
\hline & $\%$ & $77.4 \%$ & $22.6 \%$ & $20.1 \%$ & & \\
\hline
\end{tabular}

\section{Discussion}

COVID-19 pandemic is a severe challenge for healthcare physicians in the Kingdom of Saudi Arabia (KSA) [15]. Doctors are at risk of getting infected and are often under great stress thinking of the possible transmission of the infection to their family members, colleagues, and other patients [15]. Epidemiological studies done in the kingdom have reported a very high prevalence of poor sleep quality among the Saudi adult population $[16,17]$. In addition to a poor sleep quality among physicians with a prevalence of $50 \%$ or more $[18,19]$. COVID-19 has affected the mental wellbeing of health care workers that might have an impact on sleep quality [20].

The present study demonstrated that $78.1 \%$ of the doctors had good knowledge regarding COVID-19 irrespective of age, gender, position, and specialty. Another study demonstrated insufficient knowledge among doctors about this pandemic [21]. An excellent knowledge about COVID-19 is very essential among physicians when managing or treating patients [22].

The prevalence of sleep disorders among participants of this study was $43.9 \%$. A study conducted in Iraq reported a prevalence of sleepless of $68.3 \%$ [23]. Good quality sleep is very much essential to boost the immunity that would help to fight against the viruses and disease [24], and to improve doctor-patient relationship [25].

In the present study physicians had more difficulty falling asleep during COVID-19. Impaired sleep due to high work demands, irregular break-times, and stress may cause clinical burnout in healthcare workers [26]. Sleep disorders were significantly more in physicians who had an age ranging from 31-40 years. This finding is consistent with another study [27]. Also, it was found that residents and the associate consultants had significantly more sleep disorders than others. Young physicians especially residents or associate consultants may be experiencing such a pandemic for the first time, this may force them to sleep in the hospital and lead to sleep deprivation.

The study findings also showed that the trouble staying awake while driving, eating meals, or engaging in social activity was found to be more in resident doctors. Previous studies reported that that physicians who had 
Table 3 Sleep characteristics and its relationship with Sociodemographic characters

\begin{tabular}{|c|c|c|c|c|c|c|}
\hline Variable & $\mathrm{N}$ & $\%$ & Gender & Age & Position & Specialty \\
\hline \multicolumn{7}{|c|}{ Difficulty to fall asleep within 30 minutes during the COVID-19 } \\
\hline Less than once a week & 108 & 23.4 & 0.066 & 0.221 & 0.471 & 0.002 \\
\hline Not during the past two months & 130 & 28.1 & & & & \\
\hline Once or twice a week & 110 & 23.8 & & & & \\
\hline Three or More times a week & 114 & 24.7 & & & & \\
\hline \multicolumn{7}{|c|}{ Difficulty to fall asleep within 30 minutes before the COVID-19 } \\
\hline Less than once a week & 114 & 24.7 & 0.588 & 0.518 & 0.022 & 0.115 \\
\hline Not at all & 189 & 40.9 & & & & \\
\hline Once or twice a week & 112 & 24.2 & & & & \\
\hline Three or More times a week & 47 & 10.2 & & & & \\
\hline \multicolumn{7}{|l|}{ Taking pills to get sleep } \\
\hline Less than once a week & 79 & 17.1 & 0.569 & 0.045 & 0.075 & 0.028 \\
\hline Not during the past two months & 318 & 68.8 & & & & \\
\hline Once or twice a week & 47 & 10.2 & & & & \\
\hline Three or More times a week & 18 & 3.9 & & & & \\
\hline \multicolumn{7}{|c|}{ Trouble staying awake while driving, eating meals or engaging in social activity } \\
\hline Less than once a week & 96 & 20.8 & 0.069 & 0.195 & 0.002 & 0.087 \\
\hline Not during the past two months & 274 & 59.3 & & & & \\
\hline Once or twice a week & 64 & 13.9 & & & & \\
\hline Three or More times a week & 28 & 6.1 & & & & \\
\hline \multicolumn{7}{|l|}{ Sleep duration during COVID-19 } \\
\hline$<6 \mathrm{~h}$ & 176 & 38.1 & 0.211 & 0.097 & 0.000 & 0.009 \\
\hline $6-8 h$ & 232 & 50.2 & & & & \\
\hline$>8 \mathrm{~h}$ & 54 & 11.7 & & & & \\
\hline \multicolumn{7}{|l|}{ Sleep duration before COVID-19 } \\
\hline$<6 h$ & 149 & 32.3 & 0.083 & 0.185 & 0.320 & 0.021 \\
\hline $6-8 \mathrm{~h}$ & 266 & 57.6 & & & & \\
\hline$>8 \mathrm{~h}$ & 47 & 10.2 & & & & \\
\hline \multicolumn{7}{|l|}{ Sleep quality during the pandemic } \\
\hline Very good & 108 & 23.4 & 0.027 & 0.113 & 0.455 & 0.056 \\
\hline Fairly good & 277 & 60.0 & & & & \\
\hline Fairly bad & 61 & 13.2 & & & & \\
\hline Very bad & 16 & 3.5 & & & & \\
\hline
\end{tabular}

sleep deprivation are at increased risk of facing motor accidents while driving $[28,29]$.

The prevalence of sleep disorder during COVID19 was high among physicians belong to emergency medicine, anesthesia, and Laboratory/Pathology/ Microbiology. It is somehow clear that doctors working in laboratories have been working diligently during the last few months giving more priorities for the COVID-19 tests than other routine tests [30]. Sleep quality assessment showed that female physicians had poor sleep quality compared to males. A result revealed from a previous study [30]. Thus, risks of committing medical errors in physicians who have sleep deprivation are more due to cognitive and motor impairment [31, 32]. All these problems arise from a shortage of staff in the respective departments that force the doctors to work for prolonged hours than their actual work hours [33]. During a pandemic, the shortage of medical staff may become worse as some doctors may abstain from work due to fear of getting infected [33].

The hospital administrations should provide optimal work hours with enough break or leisure time, employing more doctors during this pandemic, monitor the doctor-patient ratio, educational and training programs to reduce stress among doctors. 


\section{Limitations}

The study didn't check the influence of many factors as total working hours/week and substances abuse. The selfreporting questionnaire may have a recall bias.

\section{Supplementary information}

Supplementary information accompanies this paper at https://doi. org/10.1186/s13104-020-05341-6.

Additional file 1: Figure S1. Knowledge about COVID-19 among different specialities. Figure S2. Prevalence of sleep disorders according to specialties.

\section{Abbreviations}

SARS: Severe Acute Respiratory Syndrome; MERS-CoV: Middle East Respiratory Syndrome Coronavirus; PSQI: Pittsburgh Sleep Quality Index scale; SD: Standard deviation; KSA: Kingdom of Saudi Arabia.

\section{Acknowledgements}

The authors gratefully acknowledge the cooperation of all participants.

\section{Authors' contributions}

YHA: designed the study, wrote the protocol and planed the study. He wrote the manuscript. He helped in statistical design, analysis, data entry and data collection. HAA: designed the study, wrote the manuscript, helped in statistical design and analysis, also helped in data collection. She will take the primary responsibility in responding to the reviewers' comments. HAA and SHA: designed the study, wrote the manuscript, helped in statistical design and analysis, also helped in data collection. MMA and RHA: helped in study development. They helped in data collection, data entry, and the statistical design and analysis. RMA and MAA: helped in prepared and development of the study. They were supervisors from the center. RMA: Helped and assessed in the study development, progression and supervision. All authors read and approved the final manuscript.

\section{Funding}

None.

\section{Availability of data and materials}

The datasets used and/or analysed during the current study are available from the corresponding author on reasonable request.

\section{Consent for publication}

All authors declare that the content of the manuscript has not been published, or submitted for publication elsewhere.

\section{Competing interests}

All authors declare that this manuscript is not submitted to any special issue.

\section{Author details}

1 Department of Internal Medicine, KSA, Taif University, Taif, Saudi Arabia.

${ }^{2}$ Medical Student, KSA, Taif University, Taif, Saudi Arabia. ${ }^{3}$ Department of Internal Medicine, KAMC, Makkah city, KSA, Saudi Arabia.

Received: 17 September 2020 Accepted: 14 October 2020 Published online: 21 October 2020

\section{References}

1. Ramadan N, Shaib H. Middle east respiratory syndrome coronavirus (MERS-CoV): a review. Germs. 2019;9(1):35-42.

2. Zhong NS, Zheng BJ, Li YM, Xie ZH, Chan KH, Li PH, Tan SY, Chang Q, Xie JP, Liu XQ, Xu J, Li DX, Yuen KY, Guan Y. Epidemiology and cause of severe acute respiratory syndrome (SARS) in Guangdong, People's Republic of China, in February, 2003. Lancet. 2003;362(9393):1353-8.
3. Chatterjee P, Nagi N, Agarwal A, Agarwa A, Das B, Banerjee S, et al. The 2019 novel coronavirus disease (COVID-19) pandemic: a review of the current evidence. Indian J Med Res. 2020;151(2 \& 3):147-59.

4. Lai THT, Tang EWH, Chau SKY, Fung KSC, Li KKW. Stepping up infection control measures in ophthalmology during the novel coronavirus outbreak: an experience from Hong Kong. Graefes Arch Clin Exp Ophthalmol. 2020;258(5):1049-55.

5. Wang D, Hu B, Hu C, Zhu F, Liu X, Zhang J, et al. Clinical characteristics of 138 hospitalized patients with 2019 novel coronavirus-infected pneumonia in Wuhan China. JAMA. 2020;323(11):1061-9.

6. Huang C, Wang Y, Li X, Ren L, Zhao J, Hu Y, et al. Clinical features of patients infected with 2019 novel coronavirus in Wuhan China. Lancet. 2020:395(10223):497-506.

7. Shang Y, Pan C, Yang X, Zhong M, Shang X, Wu Z, et al. Management of critically ill patients with COVID-19 in ICU: statement from front-line intensive care experts in Wuhan, China. Ann Intensive Care. 2020;10(1):73-97.

8. Grover S, Dua D, Sahoo S, Mehra A, Nehra R, Chakrabarti S. Why all COVID19 hospitals should have mental health professionals: the importance of mental health in a worldwide crisis! Asian J Psychiatr. 2020;51:102147.

9. Thorpy MJ. Classification of sleep disorders. Neurotherapeutics. 2012;9(4):687-701.

10. Maunder RG, Lancee WJ, Balderson KE, Bennett JB, Borgundvaag B, Evans $\mathrm{S}$, et al. Long-term psychological and occupational effects of providing hospital healthcare during SARS outbreak. Emerg Infect Dis. 2006;12(12):1924-32.

11. Huang Y, Zhao N. Generalized anxiety disorder, depressive symptoms and sleep quality during COVID-19 outbreak in China: a web-based crosssectional survey. Psychiatry Res. 2020;288:112954.

12. Liu N, Zhang F, Wei C, Jia Y, Shang Z, Sun L, et al. Prevalence and predictors of PTSS during COVID-19 outbreak in China hardest-hit areas: gender differences matter. Psychiatry Res. 2020;287:112921.

13. Buysse DJ, Reynolds CF 3rd, Monk TH, Berman SR, Kupfer DJ. The Pittsburgh Sleep Quality Index: a new instrument for psychiatric practice and research. Psychiatry Res. 1989;28(2):193-213.

14. Cappelleri JC, Bushmakin AG, McDermott AM, Sadosky AB, Petrie CD, Martin S. Psychometric properties of a single-item scale to assess sleep quality among individuals with fibromyalgia. Health Qual Life Outcomes. 2009;7:54-61.

15. Medic G, Wille M, Hemels ME. Short- and long-term health consequences of sleep disruption. Nat Sci Sleep. 2017;9:151-61.

16. Ahmed AE, Al-Jahdali F, AlALwan A, Abuabat F, Salih SA, Al-Harbi A, et al. Prevalence of sleep duration among Saudi adults. Saudi Med J. 2017;38(3):276-83.

17. Almojali Al, Almalki SA, Alothman AS, Masuadi EM, Alaqeel MK. The prevalence and association of stress with sleep quality among medical students. J Epidemiol Glob Health. 2017;7(3):169-74.

18. Al-Saif HI. Prevalence of and risk factors for poor sleep quality among residents in training in KSA. J Taibah Univ Med Sci. 2018;14(1):52-9.

19. Zeng LN, Yang Y, Wang C, Li X, Xiang Y, Hall BJ, et al. Prevalence of poor sleep quality in nursing staff: a meta-analysis of observational studies. Behav Sleep Med. 2019;1:1-14.

20. Preti E, Di Mattei V, Perego G, Ferrari F, Mazzetti M, Taranto P, et al. The psychological impact of epidemic and pandemic outbreaks on healthcare workers: rapid review of the evidence. Curr Psychiatry Rep. 2020;22(8):43-65

21. Bhagavathula AS, Aldhaleei WA, Rahmani J, Mahabadi MA, Bandari DK. Knowledge and perceptions of COVID-19 among health care workers: cross-sectional study. JMIR Public Health Surveill. 2020;6(2):19160.

22. Liu Q, Luo D, Haase JE, Guo Q, Wang XQ, Liu S, et al. The experiences of health-care providers during the COVID-19 crisis in China: a qualitative study. Lancet Glob Health. 2020;8(6):e790-8.

23. Abdulah DM, Musa DH. Insomnia and stress of physicians during COVID19 outbreak. Sleep Medicine: X. 2020;20:100017.

24. Besedovsky L, Lange T, Born J. Sleep and immune function. Pflugers Arch. 2012;463(1):121-37.

25. Azzez SS, Abdulah DM, Piro RS, Miho Alhakem SS. Sleep severity and fatigue manifestations in relation to the doctor-patient relationship. Sleep Med. 2019;58:13-7.

26. Söderström M, Jeding K, Ekstedt M, Perski A, Akerstedt T. Insufficient sleep predicts clinical burnout. J Occup Health Psychol. 2012;17(2):175-83. 
27. Yasin R, Muntham D, Chirakalwasan N. Uncovering the sleep disorders among young doctors. Sleep Breath. 2016;20(4):1137-44.

28. Comondore VR, Wenner JB, Ayas NT. The impact of sleep deprivation in resident physicians on physician and patient safety: is it time for a wakeup call? BCMJ. 2008;50:560-4.

29. Barger LK, Cade BE, Ayas NT, Cronin JW, Rosner B, Speizer FE, et al. Extended work shifts and the risk of motor vehicle crashes among interns. N Engl J Med. 2005;352:125-34.

30. Boccabella A, Malouf J. How Do Sleep-Related Health Problems Affect Functional Status According to Sex? J Clin Sleep Med. 2017;13(05):685-92

31. Fletcher KE, Underwood W 3rd, Davis SQ, Mangrulkar RS, McMahon LF Jr, Saint S, et al. Effects of work hour reduction on residents' lives: a systematic review. JAMA. 2005;294:1088-100.
32. Smith JW, Denny WF, Witzke DB. Emotional impairment in internal medicine house staff. Results of a national survey. JAMA. 1986;255(9):1155-8.

33. Urooj U, Ansari A, Siraj A, Khan S, Tariq H. Expectations, fears and perceptions of doctors during Covid-19 pandemic. Pak J Med Sci. 2020;36:S37-42.

\section{Publisher's Note}

Springer Nature remains neutral with regard to jurisdictional claims in published maps and institutional affiliations.
Ready to submit your research? Choose BMC and benefit from:

- fast, convenient online submission

- thorough peer review by experienced researchers in your field

- rapid publication on acceptance

- support for research data, including large and complex data types

- gold Open Access which fosters wider collaboration and increased citations

- maximum visibility for your research: over $100 \mathrm{M}$ website views per year

At BMC, research is always in progress.

Learn more biomedcentral.com/submissions 